\title{
Adherence to treatment for hypothyroidism in pregnancy and relationship with thyrotropin control: a retrospective observational cohort study
}

\author{
Júlia Siscart ${ }^{1,2,3^{*}}$, Míriam Orós ${ }^{1,2,3}$, M. Catalina Serna ${ }^{1,2,3}$, Dani Perejón ${ }^{1,2,3}$, Leonardo Galván ${ }^{4}$ and \\ Marta Ortega ${ }^{1,3,5^{*}}$
}

\begin{abstract}
Background: Hypothyroidism is the second most common endocrinological disease during pregnancy, with percentages that can range between 3.2 and 5.5\%. A good maternal and foetal health outcome depends on thyroid hormone replacement therapy. The goal of such therapy is to maintain thyrotropin (TSH) in a range that is specific for pregnant women and varies between the trimesters of pregnancy. In our study, we wanted to analyse the adherence to hypothyroidism treatment among pregnant women and to evaluate the degree of control of the disease.

Methods: We performed a retrospective observational cohort study in pregnant women between 2012 and 2018 in the Lleida health region. Therapeutic adherence was analysed by the proportion of days covered (PDC). The relationship with other variables was assessed using the regression coefficients and their $95 \%$ confidence interval (Cl).

Results: We examined a sample of 17,281 women, representing more than $92 \%$ of the pregnant women in the Lleida health region in the period analysed. Among this sample, the mean prevalence of hypothyroidism was $6.52 \%(0.07 \%$ clinical and $6.45 \%$ subclinical). $3.3 \%$ of the 17,281 pregnant women were treated. Among them, the mean adherence score was $79.6 \pm 22.2$. Of these, $54 \%$ presented high adherence. The latter had a higher mean age and better TSH control, in comparison to the ones showing low adherence.
\end{abstract}

Conclusions: Half of the treated patients had good adherence to treatment and a better TSH control, in comparison to the others. Most of them achieved a good control at the third trimester of pregnancy.

Keywords: Pregnancy, Hypothyroidism, Levothyroxine, Thyroid stimulating hormone, Adherence to treatment

\section{Introduction}

Hypothyroidism is defined as a decrease in the function of the thyroid gland and thyroid hormone in blood (T4). During pregnancy, it is the second most prevalent disease after diabetes mellitus $[1,2]$, with percentages that

\footnotetext{
*Correspondence: jvsiscart.lleida.ics@gencat.cat; mortega.lleida.ics@gencat. cat

${ }^{1}$ Primary Care Research Institute IDIAP Jordi Gol, Catalan Institute

of Health, Lleida, Spain

Full list of author information is available at the end of the article
}

can range between 3.2 and 5.5\% in Spain, depending on the region [3, 4]. In many studies, clinical and subclinical hypothyroidism have been associated with adverse effects in pregnancy, such as miscarriage and preterm birth $[5,6]$. In addition, low T4 levels in pregnant women have been correlated with the presentation of long-term neuro-cognitive problems for the newborn $[7,8]$. Therefore, a good maternal and foetal health outcome depends on treating maternal hypothyroidism by administrating thyroid hormone (T4). The goal of treatment is to 
maintain the mother's serum TSH in the population- and trimester-specific reference range [9].

Several studies suggest that in current practice hypothyroidism may be overdiagnosed and overtreated during pregnancy. Randomized controlled clinical trials have demonstrated that treating pregnant women with subclinical hypothyroidism does not benefit either the mother or the fetus [10-12].

The World Health Organization (WHO) defines adherence as the behaviour of a person taking medications, following a diet, and/or making changes in lifestyle, in agreement with the recommendations made by health professionals [13].

There are few published studies that analyse adherence in pregnancy. In a study by the North Jutland Prescription in 2001 in Denmark, an adherence of 43\% was estimated for the treatment of various pathologies that are prevalent during pregnancy [14]. There are other studies, such as the one carried out in an Australian health centre in which the rate of non-adherence to treatment of chronic diseases was estimated at $59.1 \%$. The main causes of nonadherence were forgetfulness and concerns about possible side effects [15].

Lastly, thyroid hormone requirements increase during pregnancy and hypothyroidism is a fairly common disease with serious consequences in both pregnant women and newborns. In this context, we set the objective to analyse adherence to hypothyroid treatment in pregnant women and assess the degree of hypothyroidism control.

\section{Methods}

\section{Study design and data collection}

We performed a retrospective observational cohort study in pregnant women between 2012 and 2018 in the Lleida health region (Spain).

The data of women who gave birth at the Arnau de Vilanova Hospital from January 1, 2012 to December 31, 2018 were obtained from several different sources: the CMBD ("Conjunt Minim de Base de Dades") database, which included all single and multiple pregnancies, live births and miscarriages; the E-CAP computerized database of medical history from the Catalan Health Institute, collecting data of patients assigned to primary care units; and the database of the Servei Català de Salut, that collects the data of completed prescriptions from the Social Security. All patients are assigned an individual code ("Codi d'identificació personal") which is applied in all the databases.

\section{Study population}

As inclusion criteria, women who gave birth between January 1, 2012 and December 31, 2018 were studied. Pregnancy data from the date of the last menstrual period to the date of delivery were included; therefore, data from 2011 were reviewed for pregnant women with the delivery date in 2012 and the date of the last menstruation in 2011. Pregnant women who did not belong to the Lleida health region were excluded. To evaluate the representativeness of the sample, the percentage of births studied (births registered at the Arnau de Vilanova University Hospital in Lleida) was calculated with respect to the total births in the Lleida health region in the same period. The calculation was done according to the data obtained from the "Instituto de Estadística de Catalunya" (Idescat) (Supplementary table 1).

\section{Variables measured}

We recorded different variables: the presence of hypothyroidism, which corresponds to code E03.9 and E02 of the ICD-10; the levels of TSH and T4 in blood at each trimester of gestation using universal screening, according to the laboratory reference values, evaluated by enzyme chemo-luminescence immunoassay with the Beckman Coulter DXI 800 analyser (Table 1); and the prescription of thyroid hormone (group H03A of the Anatomical Therapeutic Chemical classification.

Other variables studied were trimester of pregnancy, calculated from the date of the last menstrual period appearing in the medical record, the age of pregnant women body mass index (BMI), diabetes mellitus, arterial hypertension, dyslipidaemia, depression, pre-eclampsia and eclampsia, miscarriage, prematurity and caesarean delivery.

\section{Therapeutic adherence}

Therapeutic adherence was analysed through the proportion of days covered (PDC) used by the "Pharmacy Quality Alliance" [16]. This proportion is defined as the percentage of days during which the patient receives thyroid hormone replacement therapy, with respect to the total period indicated by the guidelines.

Adherence during pregnancy was analysed from the date of the last menstruation period until the date of delivery, or in case of prematurity or miscarriage until the date of the end of the pregnancy.

Information on all reimbursable prescriptions was obtained from the pharmacy databases. Each prescription

Table 1 Reference values of TSH and T4 in each trimester of pregnancy according to laboratory criteria

\begin{tabular}{lll}
\hline Trimester & TSH $(\mathbf{n m o l} / \mathbf{L})$ & T4I $(\mathbf{n m o l} / \mathbf{L})$ \\
\hline First & $0.50-3.70$ & $6.70-16.30$ \\
Second & $0.31-4.35$ & $5.80-13.90$ \\
Third & $0.41-5.18$ & $6.10-15.80$ \\
\hline
\end{tabular}


records the date of issue, the active ingredient prescribed, the number of units and the quantity of each drug. The indicated dose was obtained from the prescription made in the shared medical history.

Thus, as observed in other studies [17-20], we defined three levels of therapeutic adherence: high, for patients who took more than $80 \%$ of the drug prescribed; medium, for those who took between 50 and $80 \%$; and low, for those who took $<50 \%$.

\section{Analysis of data}

A descriptive analysis was made. The numerical variables were indicated through mean and standard deviation, and the categorical variables by absolute and relative frequencies. Differences between groups were evaluated using the Student's t test or the Chi-square test, depending on whether the variables were numerical or categorical, respectively. The association of the different variables with adherence was evaluated through a multivariate lineal model; the model was built using purposeful selection of variables based on clinical relevance, using the percentage of adherence as the response variable, and the rest of the variables as predictors. Regression coefficients and $95 \%$ confidence intervals of both were calculated.

\section{Ethical aspects}

This study was approved by the ethics and clinical research committee "Institute for Primary Health Care Research Jordi Gol i Gurina (IDIAPJGol)" under the code 19/195-P. The study was conducted in accordance with the principles of the Declaration of Helsinki. Pseudonymized retrospective descriptive cross-sectional study according to Additional Provision 17.2.d LOPDGDD for research purposes, without the need to obtain the consent of the data holders, there is a technical and functional separation between the research team and the performer pseudonymization, and that the data is only accessible to the research team, and technical measures have been taken to prevent such re-identification and access by third parties. through the CMBD database ("Conjunt Minim de Base de Dades") the E-CAP computerized medical history database and the Catalan Health Service database.

\section{Results \\ Epidemiological data}

A total of 21,375 pregnant women who gave birth at the Arnau de Vilanova Hospital in Lleida between 2012 and 2018 (both included) were initially included in the study. Then, we excluded 1625 women who did not have a personal identification code (CIP), and 2469 women whose medical history was missing multiple data. The final sample comprehended 17,281 pregnant women (Fig. 1).

Of the total of 17,281 pregnant women, 1129 (6.52\%) were diagnosed with hypothyroidism: $0.07 \%$ presented with clinical disease, and $6.45 \%$ with subclinical. The mean annual prevalence of pregnant women with hypothyroidism ranged from 5.67 to $7.05 \%$. The mean age of these patients was $31.7 \pm 5.7$ years, in comparison to $30.6 \pm 5.8$ years of the rest of the study population. The BMI in patients at the beginning of pregnancy was $25 \pm 5.24 .81 .12 \%$ of these patients had one or two pregnancies during the study period. Of these, $20.8 \%, 36.3 \%$, and $3.5 \%$ were classified as medium, high, or very high

21375 pregnant women who gave birth at the Arnau de Vilanova Hospital in Lleida

1625 pregnant women who did not have a personal identification code (CIP)

2469 whose Medical history was missing multiple data

17281 pregnant women studied

Fig. 1 Sample of pregnant women studied 
risk, respectively. Finally, 3.94\% of the pregnant women with hypothyroidism had miscarriages, $6.64 \%$ preterm deliveries, $2.78 \%$ prolonged deliveries, and $16.74 \%$ underwent a caesarean section.

\section{Therapeutic adherence}

Thyroid hormone treatment was prescribed in $50.3 \%$ of the patients diagnosed with hypothyroidism. Among them, the mean adherence score was $79.6 \pm 22.2$, and $54.1 \%$ of these presented high adherence. Specifically, during the years of the study, $40.4-64.7 \%$ of the treated patients showed high adherence.

The mean age was higher in treated patients with high adherence (32.8 years) than in those with low adherence (30.7 years). This difference was statistically significant. Regarding the other chronic diseases analysed, no statistically significant differences were observed in age between treated patients with high, medium, and low adherence. There were two miscarriages in the low adherence group and none in the medium and high adherence groups (Table 2).

Figure 2 describes a multivariate analysis where statistically significant differences were observed with age: the older the patient, the greater the adherence to treatment. The rest of the related variables were not statistically significant.

\section{Value of TSH in relation to therapeutic adherence}

Among patients showing high adherence to therapy, we observed poor TSH control in $66.8 \%$ during the first trimester, which dropped to $22 \%$ in the second, and finally to $8.3 \%$ in the third. On the contrary, in the low adherence group, poor control persists in the second and third trimesters. The differences between the two groups during the second trimester are statistically significant (Table 3).

Table 2 Adherence to the treatment of hypothyroidism and association with other variables studied during pregnancy

\begin{tabular}{|c|c|c|c|c|}
\hline \multirow[t]{2}{*}{ Adherence to the treatment } & \multicolumn{3}{|c|}{$79.6 \%$ (ED 22.2) } & \multirow{2}{*}{$\begin{array}{l}N: 568 \\
N: 568\end{array}$} \\
\hline & High & Medium & Low & \\
\hline Adherence to the treatment & $306(54.1 \%)$ & $187(32.9 \%)$ & $74(13.0 \%)$ & \\
\hline Adherence per year & & & & $p: 0.830$ \\
\hline 2012 & $55(64.7 \%)$ & $17(20.0 \%)$ & $13(15.3 \%)$ & \\
\hline 2013 & $60(60.6 \%)$ & $28(28.3 \%)$ & $11(11.1 \%)$ & \\
\hline 2014 & $47(58.8 \%)$ & $24(30.0 \%)$ & $9(11.2 \%)$ & \\
\hline 2015 & $39(48.1 \%)$ & $29(35.8 \%)$ & $13(16.0 \%)$ & \\
\hline 2016 & $36(40.4 \%)$ & $44(49.4 \%)$ & $9(10.1 \%)$ & \\
\hline 2017 & $36(49.3 \%)$ & $25(34.2 \%)$ & $12(16.4 \%)$ & \\
\hline 2018 & $33(55.0 \%)$ & $20(33.3 \%)$ & $7(11.7 \%)$ & \\
\hline Age of pregnant women (years) & $32.8 \pm 4.77$ & $32.1 \pm 5.64$ & $30.7 \pm 6.24$ & p: 0.007 \\
\hline Body mass index & $24.8(5.26 \%)$ & $25.4(5.29 \%)$ & $24.4(5,62 \%)$ & $p: 0.311$ \\
\hline \multicolumn{5}{|l|}{ Association with other variables } \\
\hline Diabetes Mellitus & $46(62.2 \%)$ & $21(28.4 \%)$ & $7(9.4 \%)$ & $p: 0.301$ \\
\hline Arterial hypertension & $10(47.6 \%)$ & $8(38.1 \%)$ & $3(14.3 \%)$ & $p: 0.774$ \\
\hline Dyslipidaemia & $6(66.7 \%)$ & $2(22.2 \%)$ & $1(11.1 \%)$ & $p: 0.890$ \\
\hline Depression & $12(75.0 \%)$ & $4(25.0 \%)$ & $0(0.0 \%)$ & $p: 0.195$ \\
\hline Preeclampsia & $4(66.7 \%)$ & $2(33.3 \%)$ & $0(0.0 \%)$ & $p: 1.000$ \\
\hline Duration of the pregnancy & & & & $p: 0.129$ \\
\hline Miscarriage & $0(0.0 \%)$ & $0(0.0 \%)$ & $2(100 \%)$ & \\
\hline Preterm & $22(64.7 \%)$ & $9(26.5 \%)$ & $3(8.8 \%)$ & \\
\hline Prolonged & $7(53.8 \%)$ & $5(38.5 \%)$ & $1(7.7 \%)$ & \\
\hline At term & $215(52.5 \%)$ & $143(35.0 \%)$ & $51(12.5 \%)$ & \\
\hline Caesarean delivery & $56(50.5 \%)$ & $37(33.3 \%)$ & $18(16.2 \%)$ & $p: 0.493$ \\
\hline Risk during pregnancy & & & & p: 0.985 \\
\hline Really high & $12(54.5 \%)$ & $7(31.8 \%)$ & $3(13.6 \%)$ & \\
\hline High & $135(56.5 \%)$ & $73(30.5 \%)$ & $31(13.0 \%)$ & \\
\hline Medium & $53(55.2 \%)$ & $29(30.2 \%)$ & $14(14.6 \%)$ & \\
\hline No risk & $82(51.6 \%)$ & $54(34.0 \%)$ & $23(14.5 \%)$ & \\
\hline
\end{tabular}




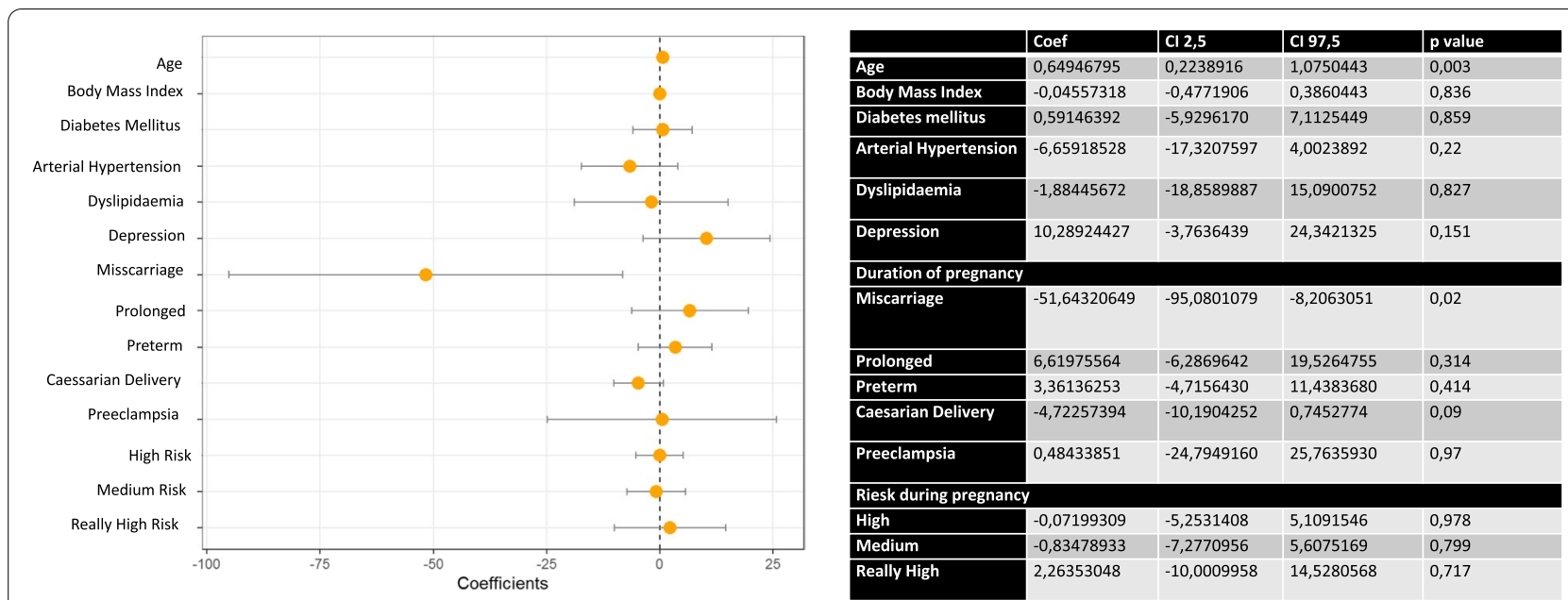

Fig. 2 Multivariate analysis of adherence to treatment for hypothyroidism and its association with other variables

Table 3 TSH values according to adherence to treatment

\begin{tabular}{llll}
\hline & High adherence & Medium adherence & Low adherence \\
\hline 1st trimester results TSH: & & \\
High & $191(66.8 \%)$ & $102(64.6 \%)$ & $41(66.1 \%)$ \\
Low & $5(1.7 \%)$ & $4(2.5 \%)$ & $0(0.0 \%)$ \\
In range & $90(31.5 \%)$ & $52(32.9 \%)$ & $21(33.9 \%)$ \\
2nd trimester results TSH: & & \\
High $58(22.0 \%)$ & $39(25.2 \%)$ & $13(31.0 \%)$ \\
Low $\quad 5(1.9 \%)$ & $2(1.3 \%)$ & $0(0.0 \%)$ \\
In range $201(76.1 \%)$ & $114(73.5 \%)$ & $29(69.0 \%)$ \\
3rd trimester results TSH: & & $6(12.2 \%)$ \\
High $\quad 18(8.3 \%)$ & $7(5.2 \%)$ & $2(4.1 \%)$ \\
Low $\quad 10(4.6 \%)$ & $3(2.2 \%)$ & $41(83.7 \%)$ \\
In range & $190(87.1 \%)$ & $125(92.6 \%)$ &
\end{tabular}

\section{Discussion}

We examined a sample of 17,281 women, representing more than $92 \%$ of the pregnant women in the Lleida health region in the period analysed. The annual prevalence of hypothyroidism was $6.53 \%$ (0.07\% clinical and $6.45 \%$ subclinical), with an oscillation between 5.67 and $7.05 \%$ in the different years. The mean age of these patients was $31.7 \pm 5.7$ years. Of the total of women in the sample, 3.3\% received hormone replacement therapy. Among them, the mean adherence score was $79.6 \pm 22.2$. Those with high adherence had a higher mean age (32.8 years), in comparison to those with low adherence (30.7 years), being this difference statistically significant. Also, treated patients with low adherence had a higher abortion rate, even if with a wide confidence interval. Finally, high adherence to treatment was associated with better TSH control during pregnancy.
The prevalence of hypothyroidism in this study is higher in comparison to some other studies conducted in Spain, such as: the study by López Espinosa et. al. in the Valencia region in 2009, where the prevalence was $3.2 \%$ [4]; or the one by Diéguez et.al. in Asturias in 2016, where the prevalence was 5.5\% (95\% CI 4.6-6.3) [3]. This variability can be explained by differences in the population studied, as well as in our study, we analysed pregnant women, whereas the others evaluated the general population. In another study in pregnant women by Jaén Díaz, JL. performed in Toledo, the prevalence of hypothyroidism was higher than the one we found $(9.5 \%, 95 \% \mathrm{CI}$ 6-14.7) [21]. Moreover, in Europe, a study carried out in Belgium by Rodrigo Moreno-Reyes et al. showed a prevalence of hypothyroidism of 7.2\% [22]. Finally, a metaanalysis in the Iranian population observed the highest prevalence of hypothyroidism during pregnancy (13.01\%, 95\% CI 9.15-18.17) [8], probably because of the lower degree of iodination in the population studied.

Various studies analysing adherence to treatment of multiple pathologies report different results. In a study in Denmark, data from the North Jutland prescription database were compared with the information provided by pregnant women through interviews carried out during the previous 120 days, and an adherence of $43 \%$ was described [14]. In agreement with it, another study on pregnant women at 36 weeks of gestation, which was carried out in Australia by means of a survey, obtained an adherence of $40.9 \%$ [15]. However, these data contrast with the ones obtained in studies that specifically analyse adherence to hypothyroid treatment in pregnant women. In this regard, in a cross-sectional multinational study carried out by Juch H. et. in 18 countries in 2016, it was reported that 39\% 
of the treated patients had high adherence (95\% CI, 32.7-45.7\%); $44.1 \%$ medium (95\% CI 12.5-22.5\%); and $16.9 \%$ low (95\% CI, 12.5-22.5\%) [20]. In our study, we observe slightly higher degree of adherence: $54 \%$ high, $32.9 \%$ medium, and $13 \%$ low. In this case, the different percentages could be due to a methodological difference: we analysed the proportion of days covered (PDC), whereas the study by Juch $\mathrm{H}$. et. al. used interviews [23].

In our study, the mean age of patients with high adherence was $32.8 \pm 4.77$ years. On the contrary, patients with low adherence were $30.7 \pm 6.24$ years old. Such difference is statistically significant, in agreement with the study by Juch $\mathrm{H}$. et. al., that significantly associated young age with low adherence in pregnant women [23]. Moreover, in the study by Briesacher et. al., the analysis of adherence to treatment for various pathologies revealed that lower adherence was associated with younger age also in the general population [24].

There are few studies where TSH control is related to therapeutic adherence. In the study by Lage MJ et. al., the authors analysed 3448 pregnant women with hypothyroidism between 18 and 49 years. They observed that $52.61 \%$ of the women had a TSH value that was in the range established by the American Thyroid Association (ATA) guidelines [25]. In this regard, we observed differences according to the trimesters of pregnancy. Indeed, the prevalence of women showing TSH value in the range oscillated between $31.5 \%$ and $33.9 \%$ in the first trimester; $69 \%$ and $76.1 \%$ in the second trimester; and $83.7 \%$ and $92.6 \%$ in the third trimester, depending on the degree of therapeutic adherence. These results indicates that a sufficient control of the disease is obtained at the third trimester by patients showing different levels of adherence to treatment.

Finally, Lee SY et. al. concluded that both clinical and subclinical hypothyroidism are associated with abortions, prematurity, and low scores in the infant cognitive evaluation; and that the risk caused by the treatment necessary to maintain TSH in a specific reference range during pregnancy is minimal [26]. In our study, there was no association between low adherence and the appearance of complications during pregnancy; this may be due to the greater adherence and greater control of TSH during the last trimester. Also, Barišić $\mathrm{T}$ et. al. suggested that early detection and optimization of hypothyroidism treatment before and during the first trimester reduces the risk of adverse pregnancy outcomes [27]. In agreement with these data, in our study, greater adherence has been associated with greater TSH control; therefore, we consider important to involve the different professionals taking care of pregnant women, to improve therapeutic adherence. In poorly controlled patients, adherence should be assessed prior to adjusting the levothyroxine dose using the information provided by the patient [28].

\section{Difficulties and limitations of the study}

Among the limitations of our study, we have to consider the loss of some cases during data collection. In particular, we missed pregnant women whose follow-up was carried out in centres that do not belong to the Social Security. However, it is estimated that they only represented around $2.2 \%$ of the total of pregnant women in the health region of Lleida [29]. Therefore, given the universal coverage of the Spanish National Health System, it is unlikely that this loss affected the results of our study.

Another limitation is that we could not to fully address the multifactorial origin of the adherence to treatment. Such multifactorial origin involve patient, family, beliefs, and psychosocial factors. All these variables should be considered in further studies.

\section{Conclusions}

In this study, $6.53 \%$ of pregnant women were diagnosed with hypothyroidism and half of the women who followed the treatment showed good adherence. Patients with higher adherence were older and had better TSH control throughout pregnancy thant those with lower adherence. Overall, a high percentage of the treated pregnant women achieved well-controlled TSH levels in the third trimester.

Among the general population, adherence to treatment for chronic diseases is a complex issue because of the multiple factors involved. In the case of pregnancy, further factors may affect the mother's decisions, such as the fear of additional adverse effects for herself and the newborn. Therefore, more evidence-based studies are necessary to provide information on the benefits of adherence to treatment.

\section{Supplementary Information}

The online version contains supplementary material available at https://doi. org/10.1186/s12884-022-04483-8.

Additional file 1. Numberof births registered in the Lleida health region by years and number of birthsin the sample studied with the percentage they represent

\section{Acknowledgements}

The authors would like to acknowledge Dr. Miquel Butí for his valuable contribution and support to design and create the database, Joaquim Sol for his contribution to the statistics analysis and Gol i Gurina Foundation. 


\section{Authors' contributions}

JS and MO conceptualised the study, analysed the data, and wrote the first draft of the manuscript; MCS contributed to the design of the study, data management, and manuscript development and review; DP contributed to the design of the study, creation of data bases, and data analysis; LG provided, validated, and helped to interpret pharmacological data; MO conceptualised the study and review of the manuscript draft. All authors read and approved the final manuscript.

\section{Funding}

The authors declare no support from any organization for the submitted work; no financial relationships with organizations that might have an interest in the submitted work in the previous three years; and no other relationships or activities that could appear to have influenced the submitted work.

\section{Availability of data and materials}

De-identified survey data will be made available by emailing a request to: jvsis cart.lleida.ics@gencat.cat.

\section{Declarations}

\section{Ethics approval and consent to participate}

This study was approved by the ethics and clinical research committee "Institute for Primary Health Care Research Jordi Gol i Gurina (IDIAPJGol)" under the code 19/195-P. The study was conducted in accordance with the principles of the Declaration of Helsinki. Pseudonymized retrospective descriptive cross-sectional study according to Additional Provision 17.2.d LOPD-GDD for research purposes, without the need to obtain the consent of the data holders, there is a technical and functional separation between the research team and the performer pseudonymization, and that the data is only accessible to the research team, and technical measures have been taken to prevent such re-identification and access by third parties. through the CMBD database ("Conjunt Minim de Base de Dades") the E-CAP computerized medical history database and the Catalan Health Service database.

\section{Consent for publication}

Not Applicable

\section{Competing interests}

The authors declare they have no competing interests.

\section{Author details \\ ${ }^{1}$ Primary Care Research Institute IDIAP Jordi Gol, Catalan Institute of Health, Lleida, Spain. ${ }^{2}$ Eixample Health Center, Catalan Institute of Health, Lleida, Spain. ${ }^{3}$ Family Medicine Department, University of Lleida, Lleida, Spain. ${ }^{4}$ Departament de Salut Spain, Lleida, Spain. ${ }^{5}$ Therapeutic Research Group in Primary Care (GRETAP), Catalan Institute of Health, Lleida, Spain.}

Received: 7 September 2021 Accepted: 7 February 2022 Published online: 01 March 2022

\section{References}

1. Blatt AJ, Nakamoto JM, Kaufman HW. National status of testing for hypothyroidism during pregnancy and postpartum. J Clin Endocrinol Metab. 2012;97(3):777-84. https://doi.org/10.1210/jc.2011-2038 Epub 2011 Dec 14 PMID: 22170721.

2. Han C, Li C, Mao J, Wang W, Xie X, Zhou W, Li C, Xu B, Bi L, Meng T, Du J, Zhang S, Gao Z, Zhang X, Yang L, Fan C, Teng W, Shan Z. High body mass index is an indicator of maternal hypothyroidism, hypothyroxinemia, and thyroid-peroxidase antibody positivity during early pregnancy. Biomed Res Int. 2015;2015:351831. https://doi.org/10.1155/2015/351831 Epub 2015 Jul 27. PMID: 26273610; PMCID: PMC4530209.

3. Diéguez M, Herrero A, Avello N, Suárez P, Delgado E, Menéndez E. Prevalence of thyroid dysfunction in women in early pregnancy: does it increase with maternal age? Clin Endocrinol (Oxf). 2016;84(1):121-6. https://doi.org/10.1111/cen.12693 Epub 2015 Jan 12 PMID: 25488673.

4. Lopez-Espinosa MJ, Vizcaino E, Murcia M, Llop S, Espada M, Seco V, Marco A, Rebagliato M, Grimalt JO, Ballester F. Association between thyroid hormone levels and 4,4'-DDE concentrations in pregnant women (Valencia, Spain). Environ Res. 2009;109(4):479-85. https://doi.org/10.1016/j. envres.2009.02.003 Epub 2009 Mar 16 PMID: 19286173.

5. Chan S, Boelaert K. Optimal management of hypothyroidism, hypothyroxinaemia and euthyroid TPO antibody positivity preconception and in pregnancy. Clin Endocrinol (Oxf). 2015;82(3):313-26. https://doi.org/10. 1111/cen.12605 Epub 2014 Oct 28 PMID: 25200555.

6. Korevaar TIM, Medici M, Visser TJ, Peeters RP. Thyroid disease in pregnancy: new insights in diagnosis and clinical management. Nat Rev Endocrinol. 2017;13(10):610-22. https://doi.org/10.1038/nrendo.2017.93 Epub 2017 Aug 4 PMID: 28776582.

7. Krassas GE, Poppe K, Glinoer D. Thyroid function and human reproductive health. Endocr Rev. 2010;31(5):702-55. https://doi.org/10.1210/er.20090041 Epub 2010 Jun 23 PMID: 20573783.

8. Sepasi F, Rashidian T, Shokri M, Badfar G, Kazemi F, Azami M. Thyroid dysfunction in Iranian pregnant women: a systematic review and metaanalysis. BMC Pregnancy Childbirth. 2020;20(1):405. https://doi.org/10. 1186/s12884-020-03040-5PMID:32664874:PMCID:PMC7386166.

9. Alexander EK, Pearce EN, Brent GA, Brown RS, Chen H, Dosiou C, Grobman WA, Laurberg P, Lazarus JH, Mandel SJ, Peeters RP, Sullivan S. 2017 Guidelines of the American Thyroid Association for the diagnosis and management of thyroid disease during pregnancy and the postpartum. Thyroid. 2017;27(3):315-89. https://doi.org/10.1089/thy.2016.0457 Erratum.In:Thyroid.2017Sep;27(9):1212.PMID: 28056690.

10. Yamamoto JM, Metcalfe A, Nerenberg KA, Khurana R, Chin A, Donovan LE. Thyroid function testing and management during and after pregnancy among women without thyroid disease before pregnancy. CMAJ. 2020;192(22):E596-602. https://doi.org/10.1503/cmaj.191664.

11. Yamamoto JM, Benham JL, Nerenberg KA, et al. Impact of levothyroxine therapy on obstetric, neonatal and childhood outcomes in women with subclinical hypothyroidism diagnosed in pregnancy: a systematic review and metaanalysis of randomised controlled trials. BMJ Open. 2018;8:e022837.

12. Hales C, Taylor PN, Channon S, et al. Controlled antenatal thyroid screening II: effect of treating maternal sub-optimal thyroid function on child behaviour. J Clin Endocrinol Metab. 2020;105:e417-27.

13. World Health Organization. Adherence to long term therapies- evidence for action. 2009.

14. Olesen C, Søndergaard C, Thrane N, Nielsen GL, de Jong-van den Berg L, Olsen J, EuroMAP Group. Do pregnant women report use of dispensed medications? Epidemiology. 2001;12(5):497-501. https://doi.org/10.1097/ 00001648-200109000-00006 PMID: 11505166.

15. Sawicki E, Stewart K, Wong S, Leung L, Paul E, George J. Medication use for chronic health conditions by pregnant women attending an Australian maternity hospital. Aust N Z J Obstet Gynaecol. 2011;51(4):333-8. https://doi.org/10.1111/j.1479-828X.2011.01312.x Epub 2011 Apr 18 PMID: 21806573.

16. Pharmacy Quality Alliance. PQA medication quality measures in the health insurance marketplace. Alexandria (VA): PQA; 2015.

17. Hepp Z, Lage MJ, Espaillat R, Gossain V. The association between adherence to levothyroxine and economic and clinical outcomes in patients with hypothyroidism in the US. J Med Econ. 2018;21(9):912-9. https:// doi.org/10.1080/13696998.2018.1484749 Epub 2018 Jun 22 PMID: 29865926.

18. Dunlay SM, Eveleth JM, Shah ND, McNallan SM, Roger VL. Medication adherence among community-dwelling patients with heart failure. Mayo Clin Proc. 2011; 86(4):273-81. https://doi.org/10.4065/mcp.2010. 0732Epub 2011 Mar 9. PMID: 21389248; PMCID: PMC3068886.

19. Huber CA, Rapold R, Brüngger B, Reich O, Rosemann T. One-year adherence to oral antihyperglycemic medication and risk prediction of patient outcomes for adults with diabetes mellitus: An observational study. Medicine (Baltimore). 2016;95(26):e3994. https://doi.org/10.1097/MD.00000 00000003994PMID:27368004;PMCID:PMC4937918.

20. Hedna K, Hakkarainen KM, Gyllensten H, Jönsson AK, AnderssonSundell K, Petzold M, Hägg S. adherence to antihypertensive therapy and elevated blood pressure: should we consider the use of multiple medications? PLoS One. 2015;10(9):e0137451. https://doi.org/10.1371/journal.pone. 0137451PMID:26359861:PMCID:PMC4567373.

21. JaénDíaz Jl, de Castro FL, Cordero García B, SantillanaBalduz F, Sastre Marcos J, Dal Gesso CM. Thyroid disorders and iodine nutritional status in the first trimester of pregnancy. Endocrinol Nutr. 2008;55(5):196-201. https:// 
doi.org/10.1016/S1575-0922(08)70668-5 English, Spanish Epub 2008 Oct 15. PMID: 22967913

22. Moreno-Reyes R, Glinoer D, Van Oyen H, Vandevijvere S. High prevalence of thyroid disorders in pregnant women in a mildly iodinedeficient country: a population-based study. J Clin Endocrinol Metab. 2013;98(9):3694-701. https://doi.org/10.1210/jc.2013-2149 Epub 2013 Jul 11 PMID: 23846819.

23. Juch H, Lupattelli A, Ystrom E, Verheyen S, Nordeng H. Medication adherence among pregnant women with hypothyroidism-missed opportunities to improve reproductive health? A cross-sectional, web-based study. Patient Educ Couns. 2016;99(10):1699-707. https://doi.org/10.1016/j.pec. 2016.04.006 Epub 2016 Apr 11 PMID: 27133920.

24. Briesacher BA, Andrade SE, Fouayzi H, Chan KA. Comparison of drug adherence rates among patients with seven different medical conditions Pharmacotherapy. 2008;28(4):437-43. https://doi.org/10.1592/phco.28.4. 437PMID:18363527;PMCID:PMC2737273.

25. Stagnaro-Green A, Abalovich M, Alexander E, Azizi F, Mestman J, Negro R, Nixon A, Pearce EN, Soldin OP, Sullivan S, Wiersinga W. merican Thyroid Association taskforce on thyroid disease during pregnancy and postpartum. Guidelines of the American Thyroid Association for the diagnosis and management of thyroid disease during pregnancy and postpartum. Thyroid. 2011;21(10):1081-125. https://doi.org/10.1089/thy.2011. 0087Epub 2011 Jul 25. PMID: 21787128; PMCID: PMC3472679.

26. Lee SY, Pearce EN. Testing, Monitoring, and treatment of thyroid dysfunction in pregnancy. J Clin Endocrinol Metab. 2021;106(3):883-92. https:// doi.org/10.1210/clinem/dgaa945PMID:33349844;PMCID:PMC7947825.

27. Barišić T, Mandić V, Vasilj A, Tiric D. Higher levels of thyrotropin in pregnancy and adverse pregnancy outcomes. J Matern Fetal Neonatal Med. 2019;32(17):2883-8. https://doi.org/10.1080/14767058.2018.1451509 Epub 2018 Mar 26 PMID: 29540085.

28. Pisa FE, Casetta A, Clagnan E, et al. Medication use during pregnancy, gestational age and date of delivery: agreement between maternal self-reports and health database information in a cohort. BMC Pregnancy Childbirth. 2015;15:310. https://doi.org/10.1186/s12884-015-0745-3.

29. Publicado en:«BOE» núm. 102, de 29/04/1986. Entrada en vigor: 19/05/1986. Departamento: Jefatura del Estado. Referencia: BOE-A-198610499. Permalink ELI. https://www.boe.es/eli/es///1986/04/25/14/con.

\section{Publisher's Note}

Springer Nature remains neutral with regard to jurisdictional claims in published maps and institutional affiliations.

- fast, convenient online submission

- thorough peer review by experienced researchers in your field

- rapid publication on acceptance

- support for research data, including large and complex data types

- gold Open Access which fosters wider collaboration and increased citations

- maximum visibility for your research: over $100 \mathrm{M}$ website views per year

At BMC, research is always in progress.

Learn more biomedcentral.com/submissions 